\title{
Impact of Decision-Making Styles on Leadership Styles in Business Managers
}

\author{
JAWWAD MUHAMMAD SHUJAAT \\ Government Mian Muhammad Nawaz Sharif Degree College Sargodha. \\ Email: azmpakistan786@yahoo.com \\ Tel: +923009604748
}

MUHAMMAD NAVEED RIAZ

Department of Psychology, University of Sargodha.

Email: naveed.riaz@uos.edu.pk

Tel: +923007714217

HUMAIRA YASMIN

Department of Psychology, University of Lahore.

Email: humairayasmin7.11@gmail.com

Tel: +923339810889

\begin{abstract}
The present study was sought to examine the role of rational, intuitive, dependent, avoidant, and spontaneous decision styles in the prediction of transformational, transactional, and laissez faire leadership styles. Research questionnaire were Urdu-translated versions of General Decision styles Questionnaire (Scott \& Bruce, 1995) and Multifactor Leadership Questionnaire (Bass \& Avolio, 2000). The sample of the current study consisted of 300 business managers from different regions of Pakistan. Purposive sampling was employed to collect the data. Multiple Regression analysis and Stepwise Regression analysis demonstrated impact of decision styles on leadership styles. Rational and intuitive decision style displayed positive effect and avoidant decision style displayed negative effect on transformational leadership style. Rational, intuitive, and dependent positively predicted transactional leadership style. Avoidant decision style displayed positive effect whereas rational and spontaneous decision style showed negative effect on laissez faire leadership style. The study shed light on the fact that the decisions of the leaders can be used as determining factors to assess their leadership in the business organizations.
\end{abstract}

Keywords: Decision Making Styles, Leadership Styles, Business Managers.

\section{Introduction}

Decision making is the primary activity of the managers in the modern corporate organizations (Williams, 2003). Decision quality of the managers determines their career, rewards, and job satisfaction. Along with these individual outcomes, decisions determine the destiny of the organization (Kreitner \& Kinicki, 2006). Today's dynamic business environments expect managers to be competent decision makers. A fair share of the organizational performance depends on the managers' ability to make fast, smart, widely-supported, and effective decisions. While recognizing the importance of the decision making in organizations, Singh (2001) labels decision making as "total task of the manager". 
Scott and Bruce (1995) proposed five decision styles including rational (use of logic, reasoning, and structured approaches), intuitive (reliance upon hunches, gut feelings, and instincts), dependent (reliance upon the direction and support of others), avoidant (postponing, withdrawing, and avoiding decisional responsibility), and spontaneous (impulsive, rapid, and quick decision makings. In the same manner, various leadership styles are opted by managers in organizational operations. Bass and Reggio (2006) proposed the Full Range Leadership Theory (FRLT) including transformational (visionary, courageous, inspiring, intellectually stimulating, and considering followers' individual needs), transactional (an exchange process between the leaders and followers), and laissez faire leadership (avoidance of leadership). Numerous organizational scenarios invite managers to make effective decision related to various organizational operations (Kamberg, 2001). A verity of decision styles is opted by organizational leaders (Riaz, 2009). Individuals adopt various decision styles in conjunction (Driver, Brousseau, \& Hunsaker, 1993).

\section{Literature Review}

Multiple decision strategies are opted by transformational leaders. Rational decision making is significantly positively correlated with (Tamb \& Krisknan, 2000). was also significantly positively correlated with intuition in female managers (Downey, Papageorgiou, \& Stough, 2005). Such integration of rational and intuitive choices increases self and environmental awareness. Such integration means using head (rationality) and heart (intuition) in conjunction, which results in effective choices in decision making because of the verity of insights produced by these two styles (Singh \& Greenhaus, 2004). Bass (1999) illustrates that leadership is rational and emotional alike.

Transformational leaders adopt those choices in decisions which are in the best interest of the organization. They remain consistent in effective decision making (Brower \& Balch, 2006). This is one of the many reasons that multiple decisional strategies are used by transformational leaders that they make decision for right reason in order to ensure the "best interest of the organizations (Brower \& Balch, 2006). It is an ideal style of leadership in the modern world of business and a prototypically effective leadership style in people' mindsets (Bass, 1990). Therefore, ideal leaders make a decision choice which they think is ideal for the organization, either rational or intuitive. Such leaders are true decision makers who stand ready to take risks and never avoid a decision (Avolio \& Bass, 2002).

Again, multiple decision styles are opted by transactional leaders. They are considered as true problem solvers and decision implementers. Such leaders consecutively engage in problem solving and decision making (Leavitt, 1987). Transactional leaders rely on rationality and logical thinking in decision making (Maddak \& Fulton, 1990). They are more effective in traditional management practices and are competent in promoting organizational stability (Daft \& Lane, 2002). Thus, transactional leaders do not involve in intuitive decision making which is more appropriate for promoting change in organizations rather than stability (Anderson, 2001; Hasson \& Anderson, 2001). Transactional leaders also implement dependent decision-making style. They are equipped with extrinsic motivation in leadership and are dependent upon followers' cognitions in decision making (Barbuto, Fritz, \& Mase, 2000). Such leaders make decisions which are in accordance with the expectations to their followers, which in return create satisfaction in organizational personnel (Singh \& Greenhaus, 2004).

Finally, there are leaders who avoid decisions. They are reluctant, denying, withdrawing, and avoiding the decision responsibilities (Bass, 2000; Bass \& Reggio, 2006). When organizations are in need, laissez faire leaders are absent. They fail to follow the followers' requests for help and assistance (Jones \& Rudd, 2007). Laissez leader is still there, but in impact factor, not more than a decoration peace that works nothing. Laissez faire leadership style stands on the most inactive and ineffective dimension of the FRLT (Bass \& Avolio, 2000). Laissez faire leaders never make rational decisions. Because people using avoidant decision style do not make rational decisions (Loo, 2000). Such leaders in fact do nothing for the organization and 
transfer the organizational control to subordinates by showing insensitivity, indifference, and inspontaneity in decisional scenarios (Jones \& Rudd, 2007).

According to psychological point of view, a competent leader must be an effective decision maker. Thus, decision making effectiveness splits strong leadership from its weaker counterpart (Muchensky, 2007). This discussion provides insights that decision making of a manager in fact reflects his or her leadership. Thus, decision making is the mirror image of a leader in which his or her leadership can be observed. Whether a leader is effective or ineffective, we can make inference on the bases of his or her decisions. The current inquiry aims to examine the role of decision styles in the prediction of leadership styles of the business managers. The study also aims to explore the primary, secondary, and least preferred decision style of Pakistani managers.

\section{Research Hypotheses}

H 1. Rational and intuitive decision style will positively predict transformational leadership style.

H 2. Avoidant decision style will negatively predict transformational leadership style.

H 3. Rational and dependent decision style will positively predict transactional leadership style.

H 4. Intuitive decision style will negatively predict transactional leadership style.

H 5. Avoidant decision style will positively predict laissez faire leadership style.

H 6. Rational and spontaneous decision style will negatively predict laissez faire leadership style.

\section{Analysis}

A total of 300 business managers were included in the present study. Purposive sampling technique was applied to in data collection from banks, keeping in view the inclusion criteria of minimum one year job experience and 5 employees under supervision (Tongco, 2007). Scott and Bruce (1995) developed GDMSQ and translated in Urdu by Batool (2003). The GDMSQ comprises of 25 items and measures five decision styles including rational (items $1,2,3,4,5)$, intuitive $(6,7,8,9,10)$, dependent $(11,12,13,14,15)$, avoidant (16, 17, 18, 19, 20), and spontaneous decision style (21, 22, 23, 24, 25). Bass and Avolio (2000) developed MLQ and translated in Urdu by Almas (2007). The MLQ comprises of 36 items and measures three leadership styles including transformational (items 10, 18, 21, 25, 6, 14, 23, 34, 9, 13, 26, 36, 2, 8, 30, $32,15,19,29,31$ ), transactional (items 1, 11, 16, 35, 4, 22, 24, 27, 3, 12, 17, 20), and laissez faire (items 5, $7,28,33)$.

Table 1: Reliability and Correlations

\begin{tabular}{|c|c|c|c|c|c|c|c|c|c|}
\hline Scales & & 1 & 2 & 3 & 4 & 5 & 6 & 7 & 8 \\
\hline 1. & Rational & $(.78)$ & $.42 * *$ & $.19 * *$ & $.40 * *$ & $.22 * *$ & $.29 * *$ & $18 *$ & $-.21 * *$ \\
\hline 2. & Intuitive & & $(.79)$ & $.25 * *$ & $-.48 * *$ & $.40 * *$ & $.55 * *$ & $.24 * *$ & $-.14 *$ \\
\hline 3. & Dependent & & & $(.78)$ & $.22 * *$ & $.32 * *$ & $.18 *$ & $.20 * *$ & $.19 *$ \\
\hline 4. & Avoidant & & & & $(.88)$ & $.20 *$ & $-.35 * *$ & $.24 * *$ & $17 * *$ \\
\hline 5. & Spontaneous & & & & & $(.80)$ & $.24 * *$ & $.30 * *$ & $.26 * *$ \\
\hline 6. & Transformational & & & & & & $(.81)$ & $.25^{* *}$ & $-.13 *$ \\
\hline 7. & Transactional & & & & & & & $(.78)$ & $-.20 * *$ \\
\hline 8. & Laissez-faire & & & & & & & & $(.82)$ \\
\hline
\end{tabular}

Note. Alpha reliability coefficients are given in diagonals. ${ }^{*} p<.05 . * * p<.01$.

(a) The $\Delta \mathrm{R}^{2}$ value of .278 indicates that $27.8 \%$ variance in transformational style with $F(5,294)=23.985$, $p<.001$. Results indicate that rational $(\beta=.454, p<.001)$ and intuitive style $(\beta=.137, p<.05)$ has significant positive effect whereas avoidant style $(\beta=-.168, p<.01)$ has significant negative effect on transformational leadership style. 
Table 2: Multivariate Regression analysis showing the effect of Decision Styles on Leadership Styles

\begin{tabular}{|c|c|c|c|c|c|c|c|c|}
\hline \multirow[b]{2}{*}{ Model } & \multicolumn{2}{|c|}{ (a) } & \multicolumn{2}{|c|}{ (b) } & $\begin{array}{l}\text { (c) } \\
\text { Laiss }\end{array}$ & -faire & Collinearity & stics \\
\hline & $\beta$ & $t$ & $\beta$ & $t$ & $\beta$ & $t$ & Tolerance & VIF \\
\hline Rational & .454 & $8.461 * * *$ & .318 & $5.575 * * *$ & -.152 & $2.858 * *$ & .839 & 1.192 \\
\hline Intuitive & .137 & $2.528 *$ & .208 & $3.603 * * *$ & .048 & 1.559 & .818 & 1.223 \\
\hline Dependent & .047 & .764 & .110 & $1.888 *$ & .059 & 1.089 & .807 & 1.239 \\
\hline Avoidant & -.168 & $3.002 * *$ & .053 & .892 & .469 & $8.447 * * *$ & .770 & 1.298 \\
\hline Spontaneous & .057 & 1.081 & -.014 & .253 & -.128 & $2.429 *$ & .854 & 1.170 \\
\hline$R^{2}=$ & & .290 & & .197 & & .303 & & \\
\hline$\Delta R^{2}=$ & & .278 & & .183 & & .291 & & \\
\hline$F(5,294)=$ & & $23.981 * * *$ & & $14.392 * * *$ & & $25.515 * * *$ & & \\
\hline
\end{tabular}

$* p<.05 . * * p<.01 . * * * p<.001$.

(b) The $\Delta \mathrm{R}^{2}$ value of .183 indicates that $18.3 \%$ variance in transactional style with $F(5,294)=14.392, p<$ .001 . Results indicate that rational $(\beta=.318, p<.001)$, intuitive $(\beta=.208, p<.001)$, and dependent style $(\beta=.110, p<.05)$ has significant positive effect on transactional leadership style.

(c) The $\Delta \mathrm{R}^{2}$ value of .291 indicates that $29.3 \%$ variance laissez faire style with $F(5,294)=25.515, p<$ .001 . Results indicate that avoidant style $(\beta=.469, p<.001)$ has significant positive effect whereas rational $(\beta=-.152, p<.01)$ and spontaneous style $(\beta=.128, p<.05)$ has significant negative effect on laissez faire leadership style.

Table 3: Stepwise Regression analysis showing the effect of Decision Making on Leadership Styles $(\mathrm{N}=300)$

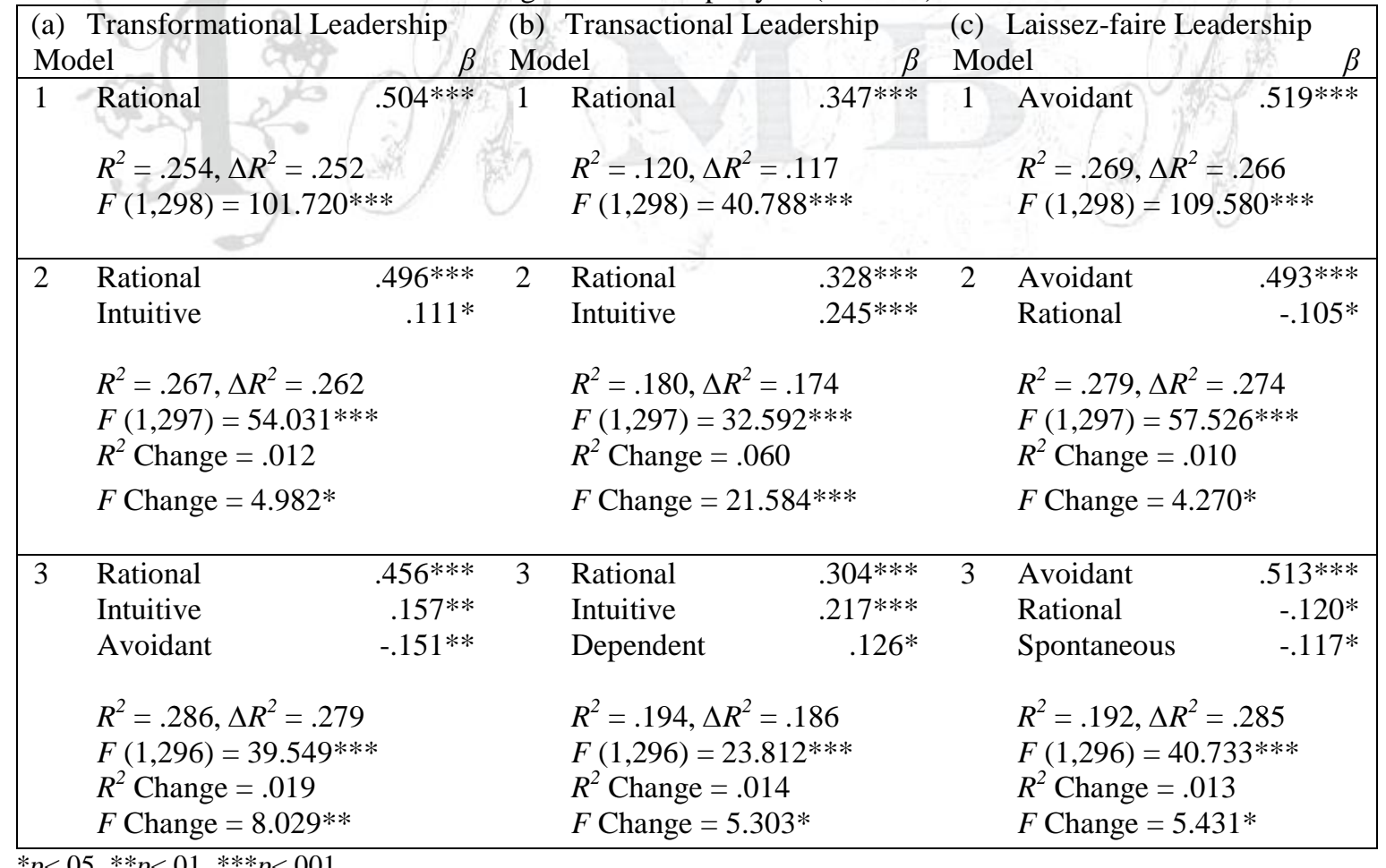

(a) Model 1 indicates that rational decision style is the best predictor of transformational leadership style. The $\Delta R^{2}$ value of .252 indicates that $25.2 \%$ variance with $F(1,298)=102.720, p<.001$. Model 2 shows 
that rational and intuitive styles are the secondary important predictors. The $\Delta R^{2}$ value of .262 indicates that $26.2 \%$ variance in the dependent variable can be accounted for, by the predictor with $F(1,297)=54.031, p$ $<.001$. The $R^{2}$ Change value of .012 indicates that intuitive style makes a significant unique contribution of $1.2 \%$ to the variance of the with $F$ Change $=4.982, p<.05$. Model 3 indicates that rational and intuitive style his significant positive effect whereas avoidant style has significant negative effect on transformational leadership styles. The $\Delta R^{2}$ value of .279 indicates that $27.9 \%$ variance with $F(1,296)=$ $39.549, p<.001$. The $R^{2}$ Change value of .019 indicates that avoidant style makes a significant unique contribution of $1.9 \%$ to the variance of the with $F$ Change $=8.029, p<.01$.

(b) Model 1 indicates that rational decision style is the best predictor of transactional leadership style. The $\Delta R^{2}$ value of .117 indicates that $11.7 \%$ variance with $F(1,298)=40.788, p<.001$. Model 2 shows that rational and intuitive styles are the secondary important predictors. The $\Delta R^{2}$ value of .174 indicates that $17.4 \%$ with $F(1,297)=32.592, p<.001$. The $R^{2}$ Change value of .060 indicates that intuitive style makes a significant unique contribution of $6 \%$ to the variance of the transactional leadership style with $F$ Change $=$ 21.584, $p<.01$. Model 3 indicates that rational, intuitive, and dependent style his significant positive effect on transactional leadership styles. The $\Delta R^{2}$ value of .186 indicates that $18.6 \%$ variance with $F(1,296)=$ 23.812, $p<.001$. The $R^{2}$ Change value of .014 indicates that dependent style makes a significant unique contribution of $1.4 \%$ to the variance of the transactional leadership style with $F$ Change $=5.303, p<.05$.

(c) Model 1 indicates that avoidant decision style is the best predictor of laissez faire leadership style. The $\Delta R^{2}$ value of .226 indicates that $22.6 \%$ variance with $F(1,298)=109.580, p<.001$. Model 2 shows that avoidant style has significant positive effect whereas rational style has significant negative effect on laissez faire leadership style. The $\Delta R^{2}$ value of .274 indicates that $27.4 \%$ variance with $F(1,297)=57.526, p<$ .001 . The $R^{2}$ Change value of .010 indicates that rational style makes a significant unique contribution of $1 \%$ to the variance of the laissez faire leadership style with $F$ Change $=4.270, p<.05$. Model 3 indicates that avoidant style has significant positive effect whereas rational and spontaneous style his significant negative effect on laissez faire leadership style. The $\Delta R^{2}$ value of .285 indicates that $28.5 \%$ variance, by the predictors with $F(1,296)=40.733, p<.001$. The $R^{2}$ Change value of .013 indicates that spontaneous style makes a significant unique contribution of $1.3 \%$ to the variance of the laissez faire leadership style with $F$ Change $=5.431, p<.05$.

\section{Discussion}

The research was carried out to study the effect of decision styles in the prediction of leadership styles. Multivariate Regression analysis indicates that from $18.3 \%$ to $29.1 \%$ variance in the dependent variables can be accounted for, by the predictors. Stepwise Regression analysis also identified the most prominent primary predictors and also explained the variance in the hypothesized direction. Most of the hypotheses were supported in the study.

The $1^{\text {st }}$ hypothesis "rational and intuitive decision styles will positively predict by transformational leadership style" was supported in the present study. The findings are consistent with the prior research that transformational leaders employ both of rational (Tamb \& Kriskhnan, 2000) and intuitive (Downey, Georgiougiou, \& Stough, 2005) decisional strategies.

The $2^{\text {nd }}$ hypothesis "avoidant decision style will negatively predict transformational leadership style" was supported the present research. The current findings are in line with the research (Downey, Georgiougiou, \& Stough, 2005) illustrating that avoidant decision style is negatively related to transformational leaders. Transformational leaders are proactive, they anticipate problems, and take initiatives to solve these problems (Bass, 1994). Thus, transformational leaders do not adopt avoidant decision style which is the byproduct of the inability to take decisional initiative (Scott \& Bruce, 1995). 
The $3^{\text {rd }}$ hypothesis "rational and dependent decision style will positively predict transactional leadership style" was supported in this study. Transactional leadership is more economic in nature in which the leader establishes a mutual exchange and economic transaction between the leader and followers to achieve organizational goals (Avolio \& Bass, 2002). Rational decision making also advocates that 'economic man' who is meximiser and uses are means to reach at an ideal end (Hyndry, 2000). Dependent decision making also displayed positive effect on transactional leadership style. Singh and Greenhaus (2004) illustrate that dependent decision style results in more productive outcomes when it is integrated with either rational or intuitive decision-making style.

The $4^{\text {th }}$ hypothesis "intuitive decision style will negatively predict transactional leadership style" was not supported in the current investigation. The contradictory findings may be due to some cultural reasons. People belonging to collectivist cultures are more likely to make intuitive decisions (Brew, Hesketh, \& Tylor, 2001). Individuals adopting intuitive decision styles are considered as satisfiers rather than maximizers (Dane \& Pratt, 2007). In the same manner, transactional leaders raise followers' morale by satisfying their needs (Daft \& Lane, 2002).

The $5^{\text {th }}$ hypothesis "avoidant decision style will positively predict laissez faire leadership style" was supported in the present study. Avoidant decision style is characterized by deficiency in self and environmental awareness (Philips, Pazienza, \& Farrin, 1984). Laissez faire leadership style is also characterized by inability to manage self and others' emotions (Gardner \& Stough, 2002).

The $6^{\text {th }}$ hypothesis "rational and spontaneous decision style will negatively predict laissez faire leadership style" was supported in this research. The findings are consistent with Loo's (2000) illustration that people opting avoidant style do not make rational choices in decisions. Thus, the avoidant laissez faire leaders are unable to make rational decisions (Bass, 1990). This is why laissez faire leadership style is regarded as the most ineffective and inactive style of leadership on the FRLT (Bass \& Reggio, 2006).

Stepwise Regression analysis confirmed the role of same predictors on the prediction of leadership styles as demonstrated by the Enter Method of Multivariate Regression analysis. But Stepwise Regression analysis helped to identify prominent predictors of the leadership styles. Rational decision style was the most prominent positive predictor of transformational leadership style. Similarly, intuitive style displayed positive effect and avoidant style displayed negative effect on the prediction of transformational leadership style. Again, rational decision style was the most prominent predictor of transactional leadership style. Intuitive and dependent decision style also displayed positive effect on transactional leadership style. Avoidant decision style was the most prominent predictor of laissez faire leadership style. Other important negative predictors included rational and spontaneous style. In future, the Hierarchal Regression analysis should be done on the basis of the insights shared by Stepwise Regression analysis.

\section{Future Recommendations}

Although the decisions of the leaders are based on the underlying situations leaders face while making a decision but the study remained limited to decision-leadership dichotomy. The future research can be extended to the inclusion of decision scenarios in the investigation of decision-leadership dichotomy. Business manager go through tough and hard decision keeping in view the complexity of the situation in the workplace.

\section{Implications of the Study}

The study is insightful in understanding the role of decision styles in the prediction of leadership styles. Decisions determine destiny of the organizations. Thus, the test of a superior leader rests in the ability to make high-graded decisions. In the light of this empirical inquiry, the decision making of the business managers should be assessed at the times of selection because this would better predict which type of 
leaders they will prove to be while supervising and leading the organizations. Leadership role and their decision-making influence and have far larger impact on the success of organization. The intelligent, informed and timely decision making give a liberty to the organization to be ahead in the competition. The aim identifies in the conducting the study carries vital significance in its stature and nature.

\section{Conclusion}

The present study was aimed at examining the role of decision styles in the prediction of leadership styles. The present study is an initiative in the world of empirical research to investigate such relationship. The findings of Multiple and Stepwise Regression analysis indicate that rational and intuitive decision making positively predicted and avoidant decision style negatively predicted transformational leadership style. Rational style was the most prominent predictor of transformational leadership. Rational, intuitive, and dependent decision style positively predicted transactional leadership style. Again, rational style was the most prominent predictor of transactional style. Avoidant decision style positively predicted whereas rational and spontaneous decision style negatively predicted laissez faire leadership style. Avoidant decision style was the most prominent predictor of laissez faire style.

\section{References}

Almas, S. (2007). Leadership styles as predictors of conflict management styles. Unpublished M. Phil dissertation, National Institute of Psychology, Quaid-iAam University Islamabad, Pakistan.

Andersen, J. A. (2000). Intuition in managers: Are intuitive managers more effective? Journal of Managerial Psychology, 15(1), 46-63.

Arroba, T. (1977). Styles of decision making and their use: An empirical study. British Journal of Guidance and Counseling, 5, 149-158.

Avoilo, B. J., \& Bass, B. M. (2002). Developing potential across a full range of leadership: Cases on transactional and transformational leadership. Mahwah, NJ: Lawrence Erlbaum.

Barbuto, J. E., Fritz, S. M., \& Marx, D. (2000). A field study of two measures of work motivation for predicting leader's transformational behaviors. Psychological Reports, 86, 295-300.

Bass, B. M. (1990). Bass and Stogdill's handbook of leadership: Theory, research, and managerial applications. New York: The Free Press.

Bass, B. M. (1994). Transformational leadership and team and organizational decision making. In B. M. Bass \& B. J. Avolio (Eds.), Improving organizational effectiveness through transformational leadership. London: Sage Publications.

Bass, B. M. (2000). The future of leadership in learning organizations. Journal of Leadership Studies, 7(3), $18-40$.

Bass, B. M., \& Avolio, B. J. (2000). Multifactor leadership questionnaire (2nd ed.). Redwood City, CA: Mind Garden.

Bass, B. M., \& Riggio, R. E. (2006). Transformational leadership. (2nd ed.). Mahwah, NJ: Lawrence Erlbaum.

Batool, N. (2003). Belief in personal control and decision-making styles of armed personnel. Unpublished M. Phil dissertation, National Institute of Psychology, Quaid-iAam University Islamabad, Pakistan.

Brew, F. P., Hesketh, B., \& Taylor, A. (2001). Individualistic-collectivist differences in adolescent decision making and decision styles with Chinese and Anglos. International Journal of Intercultural Relations, $25,1-19$.

Brower, R. W., \& Balch, B. V. (2006). Transformational Leadership \& decision making in schools. Thousands Oaks, CA: Corwin Press.

Daft, R. L., \& Lane, P. (2002). The leadership experience (2nd ed.). New York: Thomson Learning.

Dane, E. I, \& Pratt, M. G. (2007). Exploring intuition and its role in managerial decision-making. Academy of Management Review, 32, 33-54 
Downey, L. A., Papageorgiou, V., \& Stough, C. (2006). Examining the relationship between leadership, emotional intelligence and intuition in senior female managers. Leadership and Organization Development Journal, 27(4), 250-264.

Driver, M. J., Brousseau, K. E., \& Hunsaker, P. L. (1990). The dynamic decision maker. New York, NY: Harper.

Gardner, L., \& Stough, C. (2002). Examining the relationship between leadership and emotional intelligence in senior level managers. Leadership and Organization Development Journal, 23(2), 6878.

Hansson, P., \& Andersen, J. A. (2001). The Swedish Vicar and change. A problematic mismatch. The Journal of Empirical Theology, 12(1), 43-56.

Harren, V. A. (1979). A model of career decision making for college students. Journal of Vocational Behavior, 14, 119-33.

Hendry, J. (2000). Strategic decision making, discourse, and strategy as social practice. The Journal of Management Studies, 37(7), 955-977.

Hunt, R. G., Krzystofiak, F. J., Meindl, J. R., \& Yousry, A. M. (1989). Cognitive style and decision making. Organizational Behavior and Human Decision Processes, 44, 436-53.

Jones, D. W., \& Rudd, R. D. (2007). Transactional, transformational, or laissez-faire leadership: an assessment of college of agriculture academic program leaders (deans) leadership styles. Proceedings of the 2007 AAAE Research Conference, 34, 520-530.

Jung, C. G. (1971). Psychological types. The collected works of C. G. Jung, Vol. 6 Bollingen Series XX. Princeton, NJ: Princeton University Press.Kamberg, M. (2001). Making ethical business decisions. Women in Business, 532, 22-25.

Kinicki, A., \& Kreitner, R. (2006). Organizational behavior: Concepts, skills and practices (2nd ed.). New Delhi: McGraw-Hill.

Leavitt, H. J. (1987). Corporate path finders. New York: Penguin.

Loo, R. (2000). A psychometric evaluation of the general decision-making style inventory. Personality and Individual Differences, 29, 895-905.

Maddock, R. C., \& Fulton, R. L. (1998). Motivation, emotions and leadership: The silent side of management. Connecticut, NY: Quorum Books.

Mann, L., Harmoni, R., \& Power, C. (1989). Adolescent decision making: The development of competence. Journal of Adolescence, 12, 265-278.

McKenney, J. L., \& Keen, P. G. W. (1974). How Managers' minds work. Harvard Business Review, 52(3), 79-90.

Mitroff, I., \& Kilmann, R. H. (1975). Stories managers tell: A new tool for organizational problem solving. Management Review, 64, 18-28.

Muchinsky, P. M. (2007). Psychology applied to work: An introduction to industrial and organizational psychology. (8th ed.). New Delhi: Thomson Wadsworth.

Philips, S., Pazienza, N., \& Farrin, H. (1984). Decision making styles and problem-solving appraisal. Journal of Counseling Psychology, 31, 497-502.

Rowe, A. J. \& Mason, R. O. (1987). Managing with style. San Francisco: Jossey Bass Publishers.

Scott, S. G., \& Bruce, R. A. (1995). Decision-making style: The development and assessment of a new measure, Educational and Psychological Measurement, 55, 818-831.

Singh, N. (2001). Organizational behavior: Concepts, theory and practices. New Delhi: Deep \& Deep Publications.

Singh, R., \& Greenhaus, J. H. (2004). The relation between career decision-making strategies and personjob fit: A study of job changers. Journal of Vocational Behavior, 64(1), 198-221.

Tambe, A., \& Krishnan, V. R. (2000). Leadership in decision making. Indian Management, 39(5), 69-79.

Tongco MDC. 2007. Purposive sampling as a tool for informant selection. Ethnobotany Research \& Applications, 5, 147-158.

Williams, M. R. (2003). Mastering leadership: Key techniques for managing and leading a winning team (1st ed.). New Delhi: Viva Books. 